\title{
Effects of word repetition and presentation rate on the frequency of verbal transformations: Support for habituation
}

\author{
KATHARINE A. SNYDER, RICHARD S. CALEF, and MICHAEL C. CHOBAN \\ West Virginia Wesleyan College, Buckhannon, West Virginia \\ and \\ E. SCOTT GELLER \\ Virginia Polytechnic Institute and State University, Blacksburg, Virginia
}

\begin{abstract}
A verbal transformation (VT) is any perceptible change that subjects hear when the same word is repeated several times. Habituation was studied by investigating whether more VTs would occur during the second $3 \mathrm{~min}$ of word repetition. We also attempted to replicate the finding of Snyder, Calef, Choban, and Geller (1992) that a familiar word presentation style (a word spoken relatively "normally") resulted in more VTs than did an unfamiliar word presentation style (a word spoken slowly). Thirty-two psychology students listened to six neutral words repeated for 6 min with approximately 3 sec between words. Subjects reported significantly more VTs during the second as opposed to the first $3 \mathrm{~min}$ of word repetition only during normal presentation, supporting a habituation explanation that an increase in VTs following the continuous repetition of a word could be an example of habituation. We replicated the findings of Snyder et al. (1992) only during the second $3 \mathrm{~min}$.
\end{abstract}

The phenomenon of habituation-a decrease in responding to a stimulus during repeated exposure-has been researched and discussed in the context of a variety of behaviors, including the "orienting response" of infants (Moffitt, 1971), the startle reaction of pigeons (Groves \& Thompson, 1970), and human emotion (Hoffman \& Solomon, 1974; Solomon \& Corbit, 1973, 1974).

Along different lines, researchers have found that when the same word is repeated several times, subjects often report perceived changes in the word. These changes, called verbal transformations (VTs), range from perceptions of words that rhyme with the actual stimulus to more extreme phonetic distortions such as synonyms or antonyms (Calef, Calef, Kesecker, \& Burwell, 1974).

The repetition of "nonarousing" words has been found to produce more VTs than has the repetition of "arousing" words. For example, the repetition of neutral words has resulted in more VTs than has the repetition of taboo words (Calef et al., 1974); familiar words have resulted in more VTs than have less familiar words (Evans \& Kitson, 1967); more complex words have resulted in fewer VTs (Warren, 1968); and a normal presentation style has resulted in more VTs than has a slow presentation rate (Snyder, Calef, Choban, \& Geller, 1992).

Requests for reprints may be directed to R. S. Calef, Box 12, West Virginia Wesleyan College, Buckhannon, WV 26201.
Snyder et al. (1992) proposed that the latter findings were examples of a habituation effect. In other words, if an accurate auditory perception of a word is conceptualized as a private or covert response to that stimulus, then an increase in VTs following continuous repetition of a word could be construed as a decrease in responding to repeated stimulation. If the latter findings are cases of habituation, it should be of no surprise that neutral words, familiar words, less complex words, and a normal presentation style yield more VTs, since low-intensity stimuli are more susceptible to habituation than are highintensity stimuli.

In the present study, we devised a more direct test of whether an increase in VTs subsequent to the continuous repetition of a word represents a habituation phenomenon. Comparing the number of VTs for the first $3 \mathrm{~min}$ versus the second $3 \mathrm{~min}$ of word repetition for each of six neutral and familiar words under both a normal presentation rate and a slow presentation rate, we allowed for a direct test of habituation to continuous oral repetition of a word.

If the findings of the previous VT research represents a habituation effect, then more VTs should be experienced during the second $3 \mathrm{~min}$ of listening to repetitive, neutral, familiar words than during the first $3 \mathrm{~min}$. However, since Snyder et al. (1992) found that a normal presentation rate (a familiar stimulus) produced more VTs than did a slow word presentation rate (an unfamiliar stimulus), we hypothesized a greater habituation effect (more VTs during the second $3 \mathrm{~min}$ ) during the normal word presentation style. 


\section{METHOD}

\section{Subjects}

Thirty-two students from two advanced psychology courses (in experimental and physiological psychology) at West Virginia Wesleyan College served as subjects. They received 10 extra credit points toward their grades for participating.

\section{Apparatus \\ Two portable cassette stereos (Sanyo and Surround Sound), six 90-min blank TDK cassette tapes, and a stopwatch were used.}

\section{Procedure}

Two master tapes were used. Tape 1 consisted of Normal Words 1-3 on Side A and Slow Words 1-3 on Side B. Tape 2 had Normal Words 4-6 on Side A and Slow Words 4-6 on Side B. Each normal word was spoken for approximately $0.5 \mathrm{sec}$, and each slow word was spoken for approximately $1.5 \mathrm{sec}$. Approximately $3 \mathrm{sec}$ of silence occurred between each word repetition. Each word was repeated for a 6-min period with a 10-sec break after the first $3 \mathrm{~min}$. Throughout the 6-min period, each word was spoken approximately 75 times, and there was a 3 -min break before switching to a new word.

The structured data sheet, similar to that used by Calef et al. (1979), began with the following instructions:

When I switch on the recording, you will hear a word repeated for 6 min with a 10 -sec break in the middle. I want you to listen very carefully and quietly. If you think the word changes, record a check mark after the appropriate numbered trial on your data sheet, even if the change you hear does not resemble a recognizable word. If the word does not change, mark a dash after the appropriate numbered trial. After $3 \mathrm{~min}$ of word repetition, there will be a 10-sec break, which the experimenter will announce. Place a line after the last numbered trial when the experimenter announces the break. When the recording starts again after the break, begin marking your responses from the first numbered trial. For the final $3 \mathrm{~min}$, if you think the word changes, again check the appropriate numbered trial. If you do not hear a change in the word, again mark a dash after the appropriate numbered trial. After each different word, there will be a 3-min break. Repeat the above procedure for all six of the words.

Two words were printed at the top of each page, and beneath the printed words were two numbered columns with 40 spaces per column for answers. On both sets of data sheets, the words were printed in the following order: bedroom, telephone, door, people, subjects, and television (Words 1-6), and all subjects listened to these words in that order.

When the subjects arrived, they were asked to choose seats in different rows. The data sheets were handed out, and the subjects were told not to write their names on them. After reading the instructions on the first page, the experimenter asked if there were any questions and then started the tapes. The experimenter sat in the back of the room and only moved once to change the tape.

All subjects were tested in a large well-lighted lecture hall. During the 1st week, on Tuesday evening Subjects 1-8 listened to Words 1-6 under the slow presentation rate, and on Wednesday evening Subjects 9-17 listened to Words 1-6 under the normal presentation style. During the 2nd week, on Tuesday evening Subjects 18-25 listened to Words 1-6 under the slow presentation, and on Wednesday evening Subjects 26-32 listened to Words 1-6 under the normal presentation condition. Each testing period lasted approximately $75 \mathrm{~min}$. The design was a mixed 2 (first $3 \mathrm{~min}$ vs. second $3 \mathrm{~min}$ ) $\times 2$ (normal vs. slow word presentation) factorial, with stages being the within-subject factor and word presentation conditions being the between-subject factor. The total verbal transformations per subject were calculated for all conditions.

\section{RESULTS}

Table 1 illustrates the mean number of verbal transformations for the first $3 \mathrm{~min}$ and second $3 \mathrm{~min}$ of word repetition under normal versus slow presentation conditions. As depicted in Table 1, the subjects experienced substan-
Table 1

Mean Number of Total Verbal Transformations as a Function of Phase and Word Presentation Styles

\begin{tabular}{cccc}
\hline \multirow{2}{*}{$\begin{array}{c}\text { Word } \\
\text { Presentation }\end{array}$} & \multicolumn{3}{c}{ Phase } \\
\cline { 2 - 4 } Style & First & Second \\
$3 \mathrm{~min}$ & 14.25 & 15.25 & Total \\
\hline Slow & 15.69 & 23.25 & 29.50 \\
Normal & 29.94 & 38.50 & 68.94 \\
Total & & 68.44 \\
\hline
\end{tabular}

tially more VTs for the second 3 min of word repetition $(M=23.25)$ than for the first $3 \min (M=15.69)$ only under a normal word presentation rate. Under slow word presentation, subjects showed approximately the same number of VTs during the first and second 3-min phases ( $M=14.25$ and 15.25 , respectively).

During the second $3 \mathrm{~min}$, a normal presentation rate produced more VTs $(M=23.25)$ than a slow rate $(M=$ 15.25). During the first $3 \mathrm{~min}$, the frequency of VTs was approximately the same for the slow and normal presentation rates $(M=14.25$ and 15.69 , respectively).

A 2 (word presentation rate) $\times 2$ (phase) repeated measures factorial analysis of variance yielded a significant main effect of phase $[F(1,30)=7.84, p<.01]$; a nonsignificant effect of presentation rate $(p>.05)$; and a significant phase $\times$ presentation rate interaction $[F(1,30)$ $=4.60, p<.05]$. For the normal presentation rate, paired comparison CD tests showed the mean VTs during the second $3 \mathrm{~min}$ to be significantly greater $(p<.01)$ than the mean VTs during the first 3 min. However, under a slow presentation rate the CD test showed no significant $(p>.05)$ difference in mean VTs during the second $3 \mathrm{~min}$ as opposed to the first $3 \mathrm{~min}$. Also, during the second $3 \mathrm{~min}$, a normal presentation rate produced significantly more $(p<.01)$ mean VTs than did a slow presentation. However, during the first $3 \mathrm{~min}$, a normal presentation rate produced no significant difference $(p>$ .05 ) in mean VTs when compared with the slow presentation rate.

\section{DISCUSSION}

The results supported our hypothesis that more VTs would be reported for the second $3 \mathrm{~min}$ of word repetition than for the first $3 \mathrm{~min}$ of word repetition, especially during the normal word presentation rate. In fact, only for the normal presentation rate was the average number of VTs for the second 3 min significantly greater than the average number of VTs during the first $3 \mathrm{~min}$ of word repetition. Even though no main effect of presentation rate was found, the results replicated somewhat the findings of Snyder et al. (1992), in that the average number of VTs for the normal word presentation rate was significantly greater than the average number of VTs for the slow presentation rate only during the second $3 \mathrm{~min}$ of word repetition. However, it is noteworthy that Snyder et al. (1992) did not analyze the results in 3-min phases, and word presentation rate was a between-group variable in the present study but a within-group variable in the former study.

Since only under a normal word presentation rate did subjects report more VTs during the second than during the first $3 \mathrm{~min}$ of word repetition, the present study supports a habituation explanation for the previous findings of the VT research. That is, our results support the contention that previous findings (Calef et al., 1974; Evans \& Kitson, 1967; Snyder et al., 1992; and Warren, 1968) in which neutral, more famil- 
iar, less complex words and a normal word presentation rate yielded more VTs than did taboo, novel, complex words and a novel (slow) word presentation rate represent a habituation effect. In other words, when listening to the continuous repetition of a low-intensity word, subjects may have difficulty maintaining accurate perception of the word, since habituation prevents them from responding privately or covertly to the repetitive stimulus.

In the present study, habituation seemed to occur only during the second 3 min of listening to the words under a normal presentation rate. Apparently the slow presentation condition was sufficiently novel to prevent habituation from occurring during the second $3 \mathrm{~min}$.

However, before the results can be considered as indicating a lawful relationship between number of repetitions, word presentation rate, and VTs, other variables need to be investigated. For instance, it would be instructive to test whether a habituation effect (more VTs during the second 3 min of continuous repetition of a word than during the first $3 \mathrm{~min}$ ) would occur when taboo or unfamiliar words are experienced under a normal presentation rate.

One interesting implication of the present research, along with a suggestion for future study, is that this paradigm could serve as a diagnostic test for the attention deficit disorder in children. Attention deficit learning disabled (LD) children might produce fewer VTs than nonLD children (or LD children without an attention deficit) under a condition that produces VTs.

\section{REFERENCES}

Calef, R. S., Calef, R. A., Kesecker, M. P., \& Burwell, R. (1974) Verbal transformations of "stabilized" taboo and neutral words. Perceptual \& Motor Skills, 38, 177-178.
Calef, R. S., Calef, R. A., Piper, E., Shipley, D. J., Thomas, C. D., Geller, E. S. (1979). Verbal transformation as a function of boredom susceptibility, attention maintenance, and exposure time. Bulletin of the Psychonomic Society, 13, 87-89.

Evans, C. R., Kitson, A. (1967). An experimental investigation of the relation between the "familiarity" of a word and the number of changes in its perception which occur with repeated presentation as a "stabilized" auditory image. National Physical Laboratory Auto Report (Whole No. 36)

Groves, P. M., \& Thompson, R. F. (1970). Habituation: A dual-process theory. Psychological Review, 77, 419-450.

Hoffman, H. S., Solomon, R. L. (1974). An opponent-process theory of motivation: III. Some affective dynamics in imprinting. Learning \& Motivation, 5, 149-164.

MoffitT, A. R. (1971). Consonant cue perception by 20-24 week old infants. Child Development, 42, 717-731.

Snyder, K. A., Calef, R. S., Choban, M. C., Geller, E. S. (1992). Frequency of verbal transformations as a function of word-presentation styles. Bulletin of the Psychonomic Society, 30, 363-364.

Solomon, R. L., \& CoRBit, J. D. (1973). An opponent-process theory of motivation: II. Cigarette addiction. Journal of Abnormal Psychology, 81, 158-171.

Solomon, R. L., \& CoRbit, J. D. (1974). An opponent-process theory of motivation: I. The temporal dynamics of affect. Psychological Review, 81, 119-145.

WARREN, R. M. (1968). Verbal transformation effect on auditory transformation mechanisms. Psychological Bulletin, 70, 261-270.

(Manuscript received September 4, 1992.) 